\title{
The Longevity of Seeds
}

\author{
Richard H. Ellis \\ Department of Agriculture, University of Reading, Earley Gate, P. O. Box 236, \\ Reading RG6 2AT, U.K.
}

\section{INTRODUCTION}

Ewart (1908) and Harrington (1972) provided summary lists of species with seeds that were short-lived, survived for moderately long periods, or survived for very long periods. Time is only one of several variables of concern, however; seed longevity is influenced markedly by the storage environment. Ambient environments in tropical regions are generally poorer for seed storage than those of temperate regions, and so the maintenance of viability during storage is generally a greater problem in tropical regions. However, there is no need to distinguish among crop species with regard to region of production or origin when considering the physiology of seed survival. The major difference transcends these areas; it is a consequence of different responses to desiccation. Roberts (1973) classified species into two categories with regard to seed storage behavior: orthodox and recalcitrant.

Orthodox seeds tolerate considerable desiccation, and storage longevity is greatly increased thereby (Roberts, 1973). Similarly, considerable increase in orthodox seed longevity results from reduction in storage temperature, particularly since the seeds can be stored at subzero temperatures once they have been dried to a sufficiently low moisture content. These aspects of the physiology of orthodox seeds provide seedsmen with considerable scope to enhance storage life by environmental modification. If these responses are quantified, then the benefits to seed longevity can be assessed against the costs of modifying seed storage environments.

In contrast, recalcitrant seeds do not survive desiccation (Roberts, 1973; Chin, 1988). In addition, the storage temperature cannot be reduced greatly because very moist seeds are damaged by cooling to subzero (and in some cases higher) temperatures. Thus, the scope for modifying seed storage environment is limited, and so it is difficult to improve the storage life of recalcitrant seeds beyond comparatively short periods (Ring and Roberts, 1979; Roberts et al., 1984).

Fortunately, most crops have orthodox seeds (Ring and Roberts, 1979; Roberts, 1973; Roberts et al., 1984), including most

I thank T.D. Hong and E.H. Roberts for permission to report previously unpublished results, and the International Board for Plant Genetic Resources (IBPGR) for research funds. This review is based on an invited symposium lecture presented at the 1987 ASHS meeting in Orlando, Fla. of those propagated vegetatively. This category includes all of the staple food crops, the grasses, and most horticultural crops. There appear to be two main types of species with. recalcitrant seeds: a) species from aquatic habitats; and b) some of the large-seeded woody perennials. The latter category includes: a number of important tropical plantation crops such as rubber (Hevea brasiliensis Muell.-Arg.), cacao (Theobroma cacao L.), coconut (Cocos nucifera L.); many tropical fruits, e.g., avocado (Persea americana Miller), mango (Mangifera indica L.), mangosteen (Garcinia mangostana L.), durian (Durio zibenthinus Murr.), rambutan (Nephelium lappaceum L.), langsat (Lansium domesticum Corr.), jackfruit (Artocarpus heterophyllus Lam.); and various timber species from tropical (some Dipterocarpaceae and Araucariaceae) and temperate latitudes, e.g., oak (Quercus robur L.), chestnut (Castanea spp.), and horsechestnut (Аеsculus hippocastanum L.). Many more species, however, have been erroneously reported to have recalcitrant seeds (Roberts et al., 1984).

\section{ORTHODOX SEEDS}

\section{Survival curves}

Roberts (1961) showed that plotting the results of serial germination tests of subsamples of a seed lot stored under controlled conditions provides a sigmoidal curve that conforms to a negative cumulative normal distribution (Fig. 1). Thus, individual seeds within a lot die at different times and the frequency distribution of deaths is normal. It is not possible, therefore, to obtain a single measure of the longevity of a seed lot. Many authors have, however, used the time taken for germination to fall to $50 \%\left(\mathrm{p}_{50}\right)$ as a measure of longevity, an advantage of this period

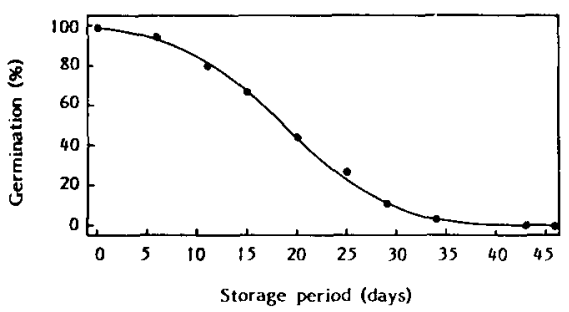

Fig. 1. Results of serial germination tests on seeds drawn from one lot of finger millet [Eleusine coracana (L.) Gaertn.) plotted against the period of hermetic storage at $40 \mathrm{C}$ with $15 \%$ moisture content ( ). The solid curve is a negative cumulative normal distribution fitted by probit analysis, being that it is the most accurately determined one (Roberts, 1972).

When the survival curves of different seed lots of a species are compared for storage under precisely the same conditions, longevity often differs, whether measured as $\mathrm{p}_{50}$ or any other viability period. Figure 2, top, provides an example of such results in cowpea [Vigna unguiculata (L.) Walp.]. However, although $\mathrm{p}_{50}$ varies, the shapes of the three curves are similar. The lower diagram shows that they are simply displaced in time (Fig. 2); i.e., the standard deviations (a) of the three curves have the same value (Ellis and Roberts, 1980a, 1981a; Ellis et al., $1982 \mathrm{~b}$ ). The standard deviation is also a period of longevity (e.g., the time taken for viability to fall from $97.7 \%$ to $84.1 \%$, or from $84.1 \%$ to $50 \%$ ). Seed survival curves that conform to negative cumulative normal distributions can be represented as straight lines if percentage germination is transformed to probits and can be quantified as follows:

$$
v=K_{i}-p / \sigma
$$

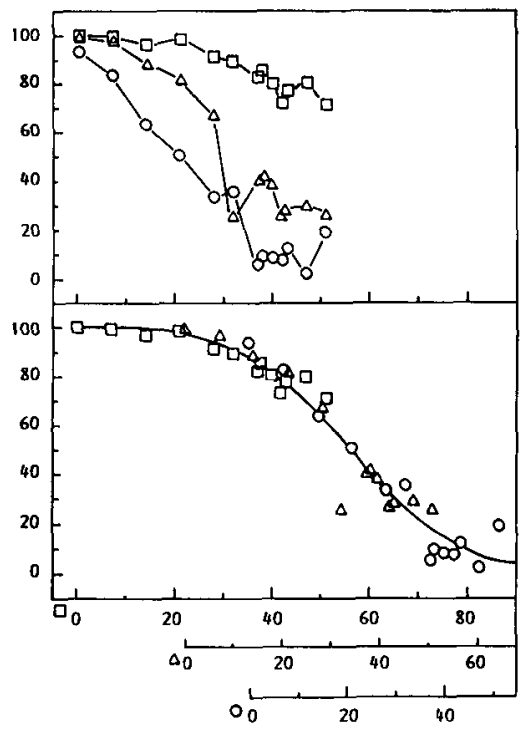

Fig. 2. Seed survival curves (percentage germination plotted against time in storage) of three lots of cowpea [Vigna unguiculata (L.) Walp.] stored at 30C with $21.0 \%$ ('Shaki Local', $\square$ ), $21.0 \%$ ('TVX 1193-10F', $\Delta$ ), or $21.5 \%$ ('Vita 4', $\bigcirc$ ) moisture content. In the lower figure absolute differences in longevity (e.g., time taken for germination to be reduced to $50 \%$ ) have been accounted for by altering the point on the time scale at which storage commenced for each lot. From Ellis et al. (1982b). 
where $v$ is probit percentage viability after $p$ days in storage, $K_{i}$ is the seed lot constant, and $\sigma$ is the standard deviation in that environment (Ellis and Roberts, 1980a). Hence, the three lots in Fig. 2 conform to the same frequency distribution of seed deaths in time; differences in $K_{i}$ are accounted for by altering the zero point of the time axis in the lower diagram.

\section{Longevity and moisture}

It has been shown for many diverse species that there is a negative logarithmic relationship between seed longevity and moisture content (Ellis and Roberts, 1980b, 1981a; Ellis et al., 1982b, 1986, 1988, 1989, 1990a, 1990c; Tompsett, 1986; Kraak and Vos, 1987). The results in Fig. 3 between $4.4 \%$ and $15.4 \%$ moisture content provide an example of this relationship; the slope, $C_{w}$ (Ellis and Roberts, 1980a, 1980b), indicates the sensitivity of longevity to differences in moisture. The value of $C_{w}$ can differ markedly among species (Ellis, 1988), largely as a result of differences in seed composition because the sensitivity of longevity to equilibrium relative humidity appears not to vary among contrasting species (Ellis et al., 1989, 1990c).

Figure 3 shows a low moisture limit to quinoa (Chenopodium quinoa Willd.) at $65 \mathrm{C}$, the critical moisture content below which further desiccation ceased to be advantageous was $4.1 \%$ (Ellis et al., 1988), while further desiccation to $1.8 \%$ was not damaging. This lower limit to the otherwise negative logarithmic relations between longevity and moisture thus provides a practical limit to seed desiccation for storage. This limit ple, from $2 \%$ in groundnut (Arachis hypogaea L.) (Ellis et al., 1990c) to $6.2 \%$ moisture content in pea (Pisum sativum L.) (Ellis et al., 1989). Nevertheless, these variant gravthese relations; interpolation shows that, for varies among orthodox species. For exam-

imetric moisture contents indicate similar equilibrium relative humidities of $\approx 10 \%$, or water potentials close to $-350 \mathrm{MPa}$ (Ellis et al., 1989, 1990a, 1990c).

There is also an upper limit to negative logarithmic relations between longevity and moisture. Villiers $(1973,1975)$ and Villiers and Edgcumbe (1975) showed in lettuce (Luctuca sativa L.) that seeds stored fully imbibed did not conform to the trend of decreasing longevity with increasing moisture. It has since been shown that the trend of decrease in lettuce seed longevity with increase in moisture continues up to $\approx 15 \%$ to 25\% (Ibrahim and Roberts, 1983; Ibrahim et al., 1983). If oxygen is freely available, further increase in moisture increases longevity, quite dramatic increases occurring as seed moisture content approaches full imbibition (Ibrahim et al., 1983). An example of such results is provided in Fig. 4 and demonstrates that the upper limit occurs whether or not oxygen is available, but that there is no improvement to longevity at higher moisture contents without the free availability of oxygen. This change in relations at high moisture contents is due to repair activities occurring within the moist seeds (Ibrahim and Roberts, 1983; Ibrahim et al., 1983). An upper limit to negative logarithmic relations between longevity and moisture has been detected in other species (Ellis and Roberts, 1977, 1981a; Ward and Powell, 1983; Petruzzelli, 1986; Zewdie and Ellis, 1991). The estimated values of this upper limit indicate that a common minimum water potential of around -14 or $-15 \mathrm{MPa}$ is required for repair (Zewdie and Ellis, 1991).

\section{Longevity and temperature}

For some time it was thought that relations between the logarithm of seed viability period and temperature at one moisture content were linear and negative (Roberts, 1961,

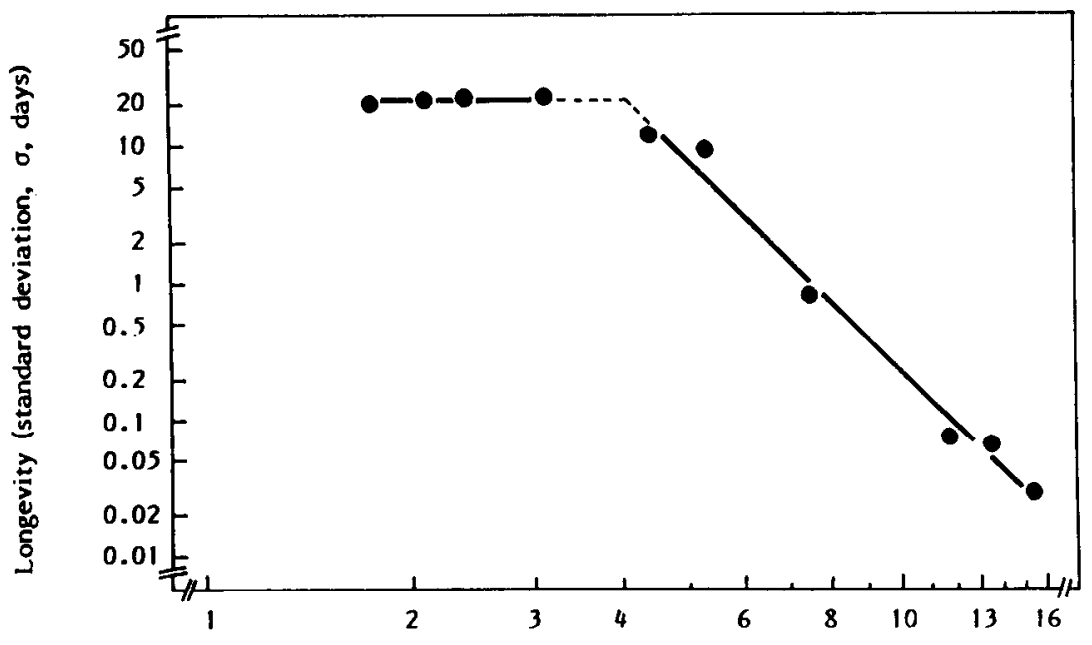

Moisture content $(\%$, wb)

Fig. 3. Relations between seed moisture content (log. scale) and the standard deviation of the frequency distribution of seed deaths in time, $\sigma(\log$. scale), for one lot of quinoa (Chenopodium quinoa Willd.) hermetically stored at $65 \mathrm{C}$. The broken lines indicate, by interpolation, the critical moisture content. From Ellis et al. (1988).

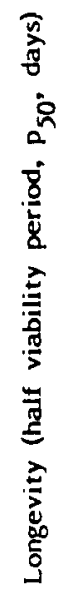

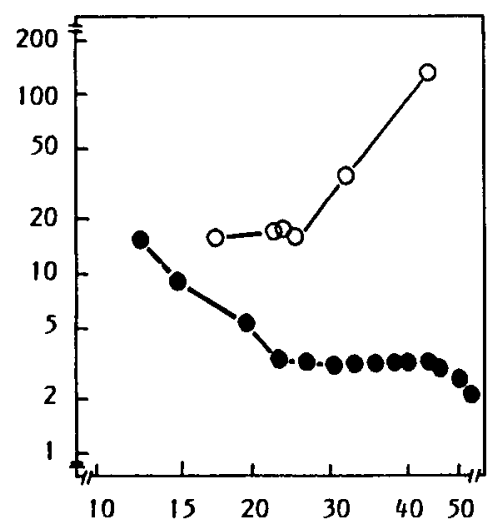

Moisture content (\%, wb)

Fig. 4. The relationship between moisture content and the time taken for the viability of lettuce seeds (Lactuca sativa L.) stored at 35C to fall to $50 \%\left(\mathrm{p}_{50}, \log\right.$. scale) when stored in sealed air-filled vials $(-)$ or under aerobic conditions ( O ). Data from Ibrahim and Roberts (1983) and Ibrahim et al. (1983).

1972; Roberts and Abdalla, 1968). One consequences of such relations is that the temperature coefficient, $Q_{l 0}$, for change in rate of loss in viability per $10 \mathrm{C}$ rise in temperature is not expected to vary with temperature (Roberts, 1972). When this was investigated in detail (initially in barley), it was found that $Q_{10}$ was not stable but increased with temperature (Ellis and Roberts, 1980a, 1980b). To quantify this variation, the basic semi-logarithmic relationship was modified by the addition of a quadratic term (Ellis and Roberts, 1980a, 1980b). It has since been shown that this model describing the relative effect of temperature on the longevity of barley seed between - 20C and 90C also explains virtually all previous, divergent reports of the value of $Q_{10}$ for a wide range of species, including cereals, legumes, vegetables, grasses, and ornamentals (Ellis and Roberts, 1981a). The basic model is applicable to other species (Ellis and Roberts, 1981a; Ellis et al., 1982b; Tompsett, 1986; Kraak and Vos, 1987) and comparison among eight contrasting species found no differences between species in the relative sensitivity of longevity to temperature (Dickie et al., 1990).

Although reduction in temperature improves longevity, the model predicts that the relative benefit declines as temperature is reduced. Initially, the lowest temperature observations against which the model had been tested were - 20C (Ellis and Roberts, 1980a, 1980b). Tompsett (1986) has suggested the model may hold down to $-75 \mathrm{C}$, the benefit to longevity from such a low temperature being slight as compared to $-20 \mathrm{C}$, but application below $-20 \mathrm{C}$ is not recommended (Dickie et al., 1990).

\section{The viability equation}

The combined influence of moisture and temperature on the reciprocal of the seed survival curve slope, i.e., the standard devia- 
tion $\sigma$, has therefore been described by the following equation:

$\log _{10} \sigma=\mathrm{K}_{\mathrm{E}}-\mathrm{C}_{\mathrm{w}} \log _{10} m-\mathrm{C}_{\mathrm{H}} t-C_{Q} t^{2}$

where $m$ is seed moisture content $(\%$, wet basis), $t$ is temperature $\left({ }^{\circ} \mathrm{C}\right)$, and $K_{E}, C_{w}$, $\mathrm{C}_{\mathrm{H}}$, and $\mathrm{C}_{0}$ are species constants (Ellis and Roberts, 1980a). Equations [1] and [2] can be combined to give

$v=K_{i}-\mathrm{p} / 10^{\mathrm{KE}}$

which enables the viability of any lot to be estimated after any period of storage in a known storage environment for any species for which appropriate values of the species constants $K_{F}, C_{w}, C_{H}$, and $C_{0}$ are known (Ellis and Roberts, 1980a, 1980b, 1981a). Dickie et al. (1990) have provided these values for eight diverse species.

If the models are useful for predictive purposes, then they should be capable of describing other workers' results (Ellis and Roberts, 1980a, 1981a). Of course, such comparisons need to take into account errors in determining the value of the seed lot constant, percentage viability after storage, and storage temperature and moisture. Nevertheless, the model for barley describes very satisfactorily earlier results (Roberts and Abdalla, 1968) for storage of another lot in nine different environments (Ellis and Roberts, 1980a), as well as more recent results for six lots each stored in six environments (Ellis and Roberts, 1981b). One particularly noteworthy and successful comparison of the model for barley with earlier results concerns those following 123 years of storage in the foundation stone of the Nuremburg City Theatre (Aufhammer and Simon, 1957). This comparison (Ellis and Roberts, 1980a) provides considerable reassurance when applying the improved viability equation for long periods.

\section{Application of the equation}

Seed viability nomographs have been prepared to aid the application of these models (Ellis and Roberts, 1980a, 1981a; Ellis, 1988). The nomograph for cowpea is shown in Fig. 5. Nomographs may be used in many ways. Calculations are made by drawing straight lines amongst scales a, b, and c; scales c, d, and e; and scales $\mathrm{f}, \mathrm{g}$, and $\mathrm{h}$. Scale $\mathrm{c}$ is a pivot point, as are scales e and $\mathrm{f}$, except that these two scales incorporate a transformation from logarithmic to linear scales. As an example of one of many possible calculations, consider the calculation of the germination of a cowpea seed lot initially showing $90 \%$ germination after 30 days of storage at $30 \mathrm{C}$ with $21 \%$ moisture content. This example calculation is shown as broken lines in Fig. 5. First join the point at 30C on scale a with $21 \%$ on scale b and continue the straight line to scale c (15 to 20 days). Connect this value to 30 days on scale $d$ and continue the straight line to scale e. The result is a loss in probit viability of between 1.5 and 2.0, say 1.7. Now mark this same value (1.7) on scale $f$ and join this to $90 \%$ initial viability on scale $h$. The straight line between these two points crosses scale $g$ at $\approx 35 \%$. Thus, 30 days of storage at $30 \mathrm{C}$ with $21 \%$ moisture content is expected to reduce germination from $90 \%$ to roughly $35 \%$. Comparison with the lower diagram in Fig. 2 between 30 and 60 days shows that this was borne out in practice. Other ways in which this quantitative information can be presented include tables showing the moisture contents to which seeds need to be dried to minimize loss in viability at different temperatures for various periods and climatographs to compare diverse sites for seed stores in terms of their effect on longevity (Ellis, 1988).

Of course the environment, and hence longevity, will be modified by the design of seed storage building (O'Dowd and Dobie, 1983). Mathematical models that describe the influence of building design on seed storage environment can be combined with Eq. [3] to enable estimation of the influence of building design on longevity (O'Dowd and Dobie, 1983; O’Dowd et al., 1988).

\section{RECALCITRANT SEEDS}

The single diagnostic feature of recalcitrant seeds is that they cannot be dried without damage (Roberts, 1973). Rubber is one of the more important crops with recalcitrant seeds (Fig. 6). Although the moisture content that impairs germination appears to vary considerably among seeds within a lot, in this example, the majority of seeds did not survive desiccation from $25 \%$ to $15 \%$, while no seed survived desiccation to $<10 \%$ (Fig. 6).

Although not a diagnostic feature of recalcitrant seeds, seed development and ger-

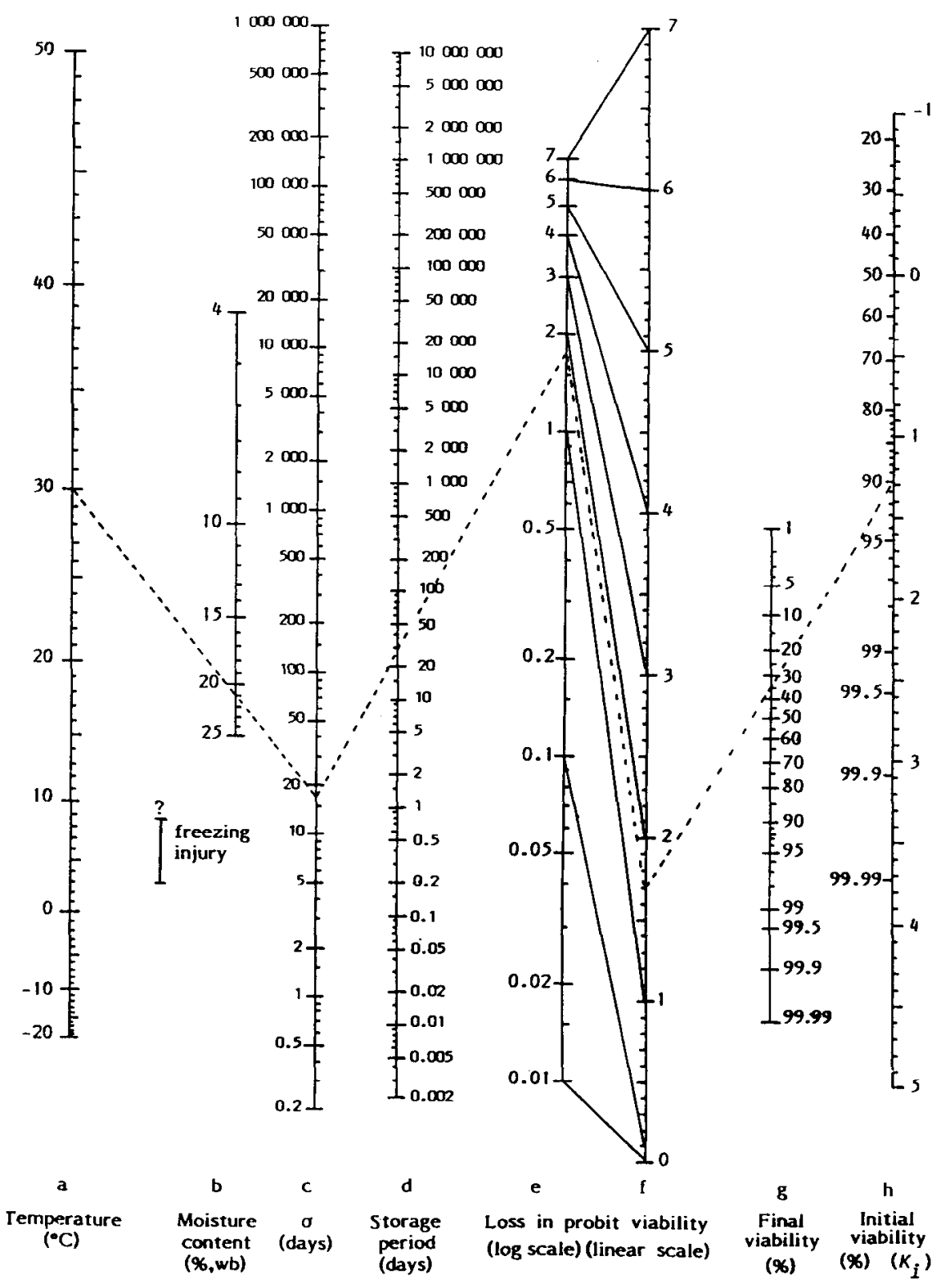

Fig. 5. Seed viability nomograph for cowpea [Vigna unguiculata (L.) Walp.]. The vertical bar between scales $a$ and $b$ provides a warning of the possibility of damage to seeds from freezing injury. An example of how to make calculations using the nomograph is provided in the text. From Ellis (1988). 


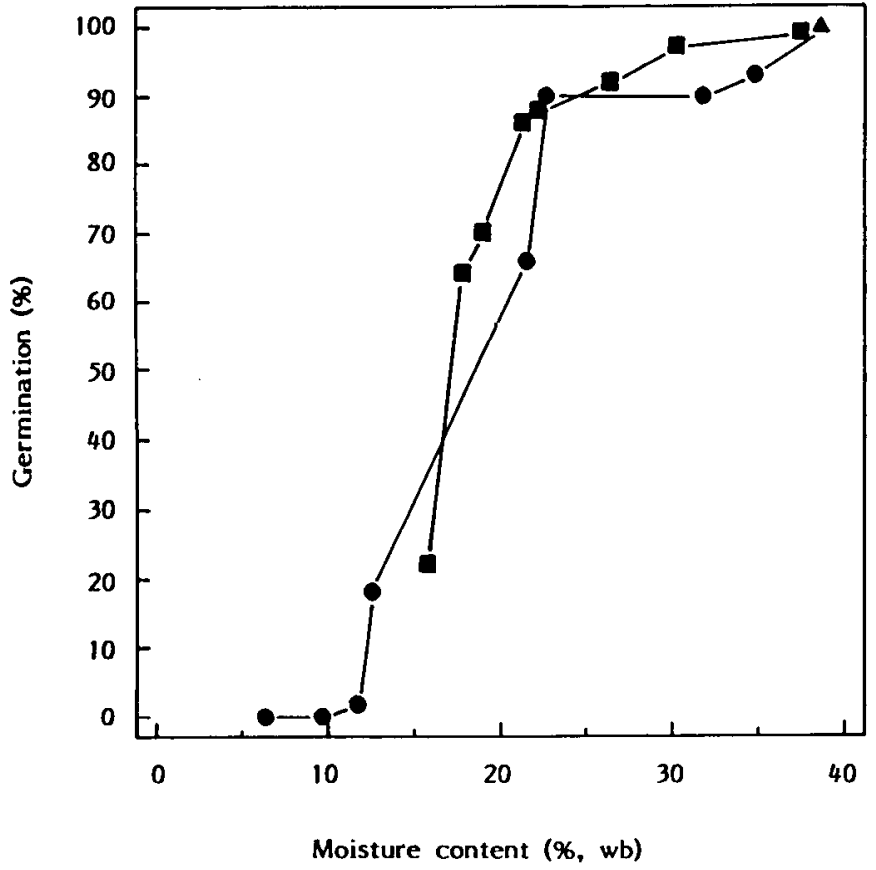

Fig. 6. Influence of desiccation on the germination of rubber seeds (Hevea brasiliensis Muell.-Arg.) not dried ( $\boldsymbol{\Delta}$ ), sundried at $28-48 \mathrm{C}$ ( $)$ ). or fan-dried in an air-conditioned room at $22 \mathrm{C}, 60 \% \mathrm{RH}$ (ם). Data from Chin et al. (1981).

mination in many of these species appear to be more of a continuum than is the case in orthodox seeds. Sometimes viviparous germination may be observed. Although recalcitrant seeds of Avicennia marina (Forsk.) Vierh. show no visible signs of vivipary, it appears that the germination processes continue after shedding (and may begin earlier), and that the damage from slow drying is similar to that observed in orthodox seeds once germination has progressed beyond the limit of desiccation-tolerance (Pammenter et al., 1984). A hypothesis to explain recalcitrant seed storage behavior has been developed from such observations (Berjak et al., 1990).

\section{Imbibed storage}

In many recalcitrant species, even shortterm storage can be difficult because of the propensity of the seeds to germinate if imbibed. However, the recalcitrant seeds of Melicoccus bijuga Jacq. and Eugenia brasiliensis Lam. were prevented from germinating, and viability was maintained for 6 months when seeds were stored fully imbibed at $15 \mathrm{C}$ with a $10^{-4} \mathrm{M}$ abscisic acid solution (Goldbach, 1979).

Orthodox seeds stored at moisture contents close to fully imbibed can survive for considerable periods if oxygen is freely available. For example, lettuce seeds maintain viability for at least 3 years at 30C under such conditions (Ibrahim et al., 1983). Is it possible to use similar conditions to maintain the viability of recalcitrant seeds?

Cacao seeds tend to lose viability if their moisture content falls below $\approx 30 \%$ (Hor et al., 1984) or $37 \%$ to $40 \%$ (King and Roberts, 1982), or if temperature falls below 17C (Hor et al., 1984). King and Roberts (1982) showed that some seeds could be maintained viable for 8 months when stored subimbibed at 20C if they were kept at $40 \%$ to $42 \%$ moisture content during a short period of initial drying and subsequently maintained at $98 \%$ relative humidity. These conditions were dramatically superior to a lower relative humidity (Fig. 7). Nevertheless, even in imbibed or subimbibed storage, the longevity of recalcitrant seeds appears short compared with that of orthodox seeds under similar conditions; i.e., recalcitrant seeds tend to be shortlived even if not dried (King and Roberts, 1979, 1980a).

\section{Seed development}

The ability of orthodox seeds to withstand rapid desiccation is attained during development and is associated with maturation drying. For example, in six grain legumes, the onset of desiccation-tolerance coincided with maturation drying that reduced seed moisture content to $\approx 60 \%$ (Ellis et al., 1987). A comparison of seed development between the orthodox Acer platanoides L. and the recalcitrant Acer pseudoplatanus L. showed that seeds of the former became desiccation tolerant once maturation drying reduced moisture contents to $54 \%$, but the latter remained intolerant of desiccation throughout development (Hong and Ellis, 1990). Thus, there is no evidence that seeds of the recalcitrant A. pseudoplatanus are orthodox at any stage of development.

Most Cucurbitaceae have orthodox seeds, but seed storage behavior is uncertain in Telfairia and Sechium (Ellis et al., 1985). Sechium edule Schwartz is one of several species in which recalcitrant seed storage behavior has been reported but for which evidence is lacking (King and Roberts, 1979). We have found that seeds that would otherwise germinate readily in the fruit do not survive desiccation to below $20 \%$ moisture content

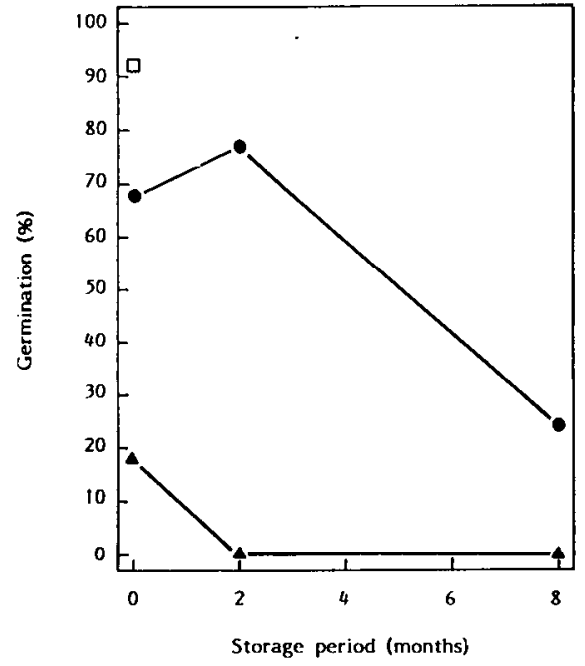

Fig. 7. The influence of $3 \mathrm{~h}$ of desiccation and subsequent storage at 20C with $98 \% \mathrm{RH}$ ( O ), or $8 \mathrm{~h}$ of desiccation and subsequent storage at $20 \mathrm{C}$ with $81 \% \mathrm{RH}$ ( $\boldsymbol{\Delta}$ ), or no desiccation with no storage $(\square)$ on the germination of cacao seeds (Theobroma cacao L.). Data from King and Roberts (1982).

(Ellis, Hong, and Roberts, unpublished). However, despite their ability to germinate, the seeds extracted were immature, with $90 \%$ moisture content. Is the damage on drying caused by premature drying?

To test this, we sought to enable seed development to progress further by holding fruits at $16 \mathrm{C}$ to $18 \mathrm{C}$ for up to 77 days. To prevent germination, fruits were dissected to expose the top of the seed, and continuous white light at a high photon fluence rate provided a treatment that inhibits germination in many Cucurbitaceae (Ellis et al., 1985). Seeds were thereby prevented from germinating and developed from immature, pale, watery, and thin to become more mature, creamy-colored, firm, and thick. These changes were associated with a 9-fold increase in dry weight and a reduction in moisture content to $50 \%$ (Fig. 8). Despite this maturation drying, however, the seeds did not survive further desiccation to below $20 \%$ moisture content. This result tends to confirm that Sechium edule is recalcitrant; but this type of treatment may form the basis of an acceptable shortterm storage procedure. These two examples demonstrate that seed development in recalcitrant species can differ markedly.

\section{ERRONEOUS CLASSIFICATION OF SEED STORAGE BEHAVIOR}

The distinction between the definitions of orthodox and recalcitrant seeds is simple. Nevertheless, several species with orthodox seeds have been erroneously reported to be intolerant to desiccation and consequently classified as recalcitrant. For example, King and Roberts (1979) classified oil palm (Elaeis guineensis Jacq.) as recalcitrant, but Grout et al. (1983) subsequently concluded they were orthodox. The misclassification of orthodox seeds as recalcitrant affects subsequent decisions on the method and costs of seed storage. 


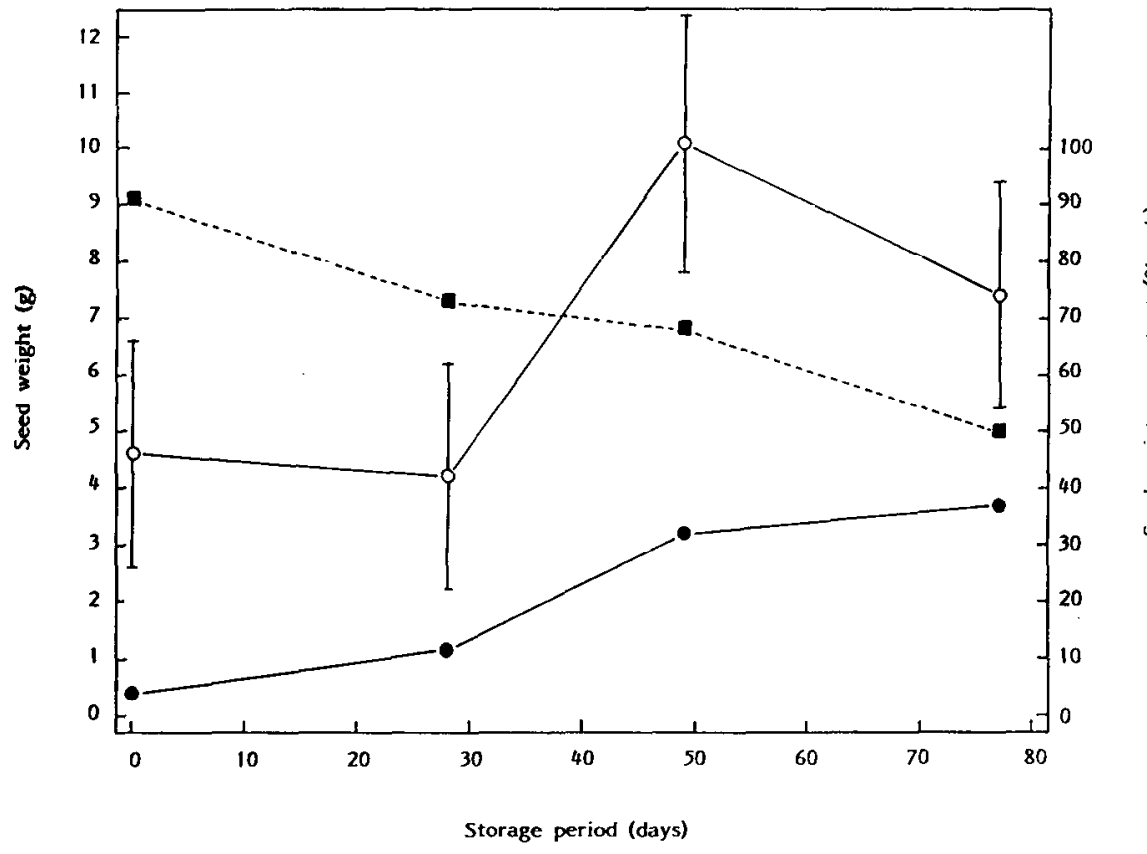

Fig. 8. Relations between mean seed fresh weight $(\mathrm{O}-\mathrm{O}$, standard errors given by vertical bars), mean seed dry weight $(\mathrm{O}-\mathrm{O})$, seed moisture content ( $----\mathbf{a})$ and the period of within-fruit storage for partially dissected fruits of chayote (Sechium edule Schwartz) maintained under continuous white light at a high photon fluence rate at 16-18C (Ellis, Hong, and Roberts, unpublished).

These enforce an artificial limit on the maximum practical period of storage and, in some cases, may deter the development of propagation by seed for crop production.

\section{Dormancy}

For example, cassava (Manihot esculenta Crantz.) is propagated vegetatively for crop production. There is now interest in developing production systems based on propagation by seed (CIAT, 1987). This change would have proved difficult if the seeds were recalcitrant, as had been suggested (Mumford and Grout, 1978), but they are in fact orthodox (Ellis and Roberts, 1979; Ellis et al., 1981). The reason for the confusion appears to be that the optimum constant temperature for germination may not remain stable during storage (Ellis and Roberts, 1979). For example, results for two lots of cassava stored at $40 \mathrm{C}$ with $6.4 \%$ or $7.2 \%$ moisture content for 8 weeks are shown in Fig. 9. Results for percentage germination following tests at 35C (Fig. 9A) could be interpreted as loss in viability during storage, but results from parallel tests at 30C (Fig. 9B) indicate that a change in the optimum constant temperature for germination occurred during storage, not a substantial loss in viability. To avoid such confusion in cassava germination tests, it is essential to use alternating temperatures so that germination reflects viability (Ellis and Roberts, 1979; Ellis et al., 1982a). Provided this is done, it is clear that the seeds can be dried to as low as $3.2 \%$ moisture content without damage, and that drying down to $4.6 \%$, and possibly less, improves longevity (Ellis et al., 1981).

\section{Delays in germination}

Citrus seeds also have been erroneously classified as recalcitrant. Seeds with intact testas at moisture contents close to fully imbibed can be slow to germinate, but desiccation results in a considerable further delay to germination (Ring and Roberts, 1980b). The delay to germination is a consequence of the time taken by the dry seeds to imbibe (Soetisna et al., 1985). This time can be reduced if the testas are removed (Ring and Roberts, 1980b). The seeds survive desiccation (Mumford and Grout, 1979; Ring and Roberts, 1980b; Ring et al., 1981; Soetisna et al., 1985). Consequently, it has been suggested that earlier erroneous reports that seeds of Citrus spp. are damaged by desiccation resulted from too short a germination test period for the dried seeds (Ring and Roberts, 1980b).

Another example where delays to germination in dry seeds could result in the erroneous classification as recalcitrant concerns Musa spp. The progress of germination over 10 months of intact seeds from two wild Musa spp. previously dried to $6 \%$ moisture content is shown in Fig. 10. No germination occurred until the 50th day. Moreover, germination only occurred following exposure to alternating temperatures. For example, a proportion of the seeds germinated after 200 days, 30 days after transfer from constant to alternating temperatures (Fig. 10). Clearly, Musa spp. cannot be recalcitrant since they survive desiccation to $6 \%$ moisture content. If, however, germination tests following drying had been concluded after, say, 6 weeks, then it might have been assumed that the seeds were recalcitrant.

\section{AN INTERMEDIATE CATEGORY OF SEED STORAGE BEHAVIOR?}

Despite many reports to the contrary, coffee (Coffea arabica L.) is not recalcitrant

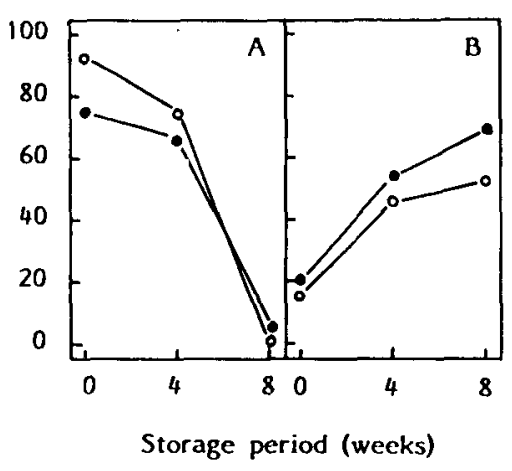

Fig. 9. Changes in the germination of two seed lots of cassava (Manihot esculenta Crantz) hermetically stored at 40C with either $6.4 \%$ ( $\bigcirc$ ) or $7.2 \%$ ( $\bigcirc$ ) moisture content when subsequently tested at constant $35 \mathrm{C}(\mathbf{A})$ or $30 \mathrm{C}$ (B). From Ellis and Roberts (1979).

(Roberts et al., 1984). For example, results from Van der Vossen (1979) show that increases in moisture content between $11 \%$ and $22 \%$ reduced longevity, whereas increases between $22 \%$ and $41 \%$ increased longevity (Fig. 11). This pattern has been shown in orthodox seeds, e.g., Fig. 4.

Many other reports have shown that, within certain limits, coffee seeds are not damaged by desiccation (Ellis et al., 1985). However, some reports have suggested that while drying to $8 \%$ moisture content was not damaging, further desiccation damaged the seeds (Ellis et al., 1985). It is now becoming clear that the divergent literature on coffee seed survival following desiccation results from differences in desiccation sensitivity among lots, which may be the result of different harvesting and processing procedures (Ellis et al., 1991a), and that seed storage behavior of coffee is neither orthodox nor recalcitrant (Ellis et al., 1990b). This conclusion was drawn because most seeds survived desiccation to $\approx 10 \%$ moisture content (or roughly - $90 \mathrm{MPa}$ ) but further desiccation generally reduced germination and always reduced longevity (Ellis et al., 1990b). Moreover, seeds stored at $15 \mathrm{C}$ with $\approx 10 \%$ moisture content more or less maintained their viability over 12 months, but longevity was reduced at $0 \mathrm{C}$ and further reduced at $-20 \mathrm{C}$ (Ellis et al., 1990b). A similar pattern of results has been detected in papaya (Carica papaya L.) (Ellis et al., 1991b). Consequently, it appears that, in addition to orthodox and recalcitrant, there is an intermediate category of seed storage behavior (Ellis et al., 1990b, 1991b).

\section{CONCLUSIONS}

Problems with seed storage are somewhat greater in tropical than in temperate regions. Ambient storage environments for orthodox seeds are in general less benign. Greater modification of seed storage environments compared with the ambient may be required than is the case in temperate regions. Moreover, advice developed from practical experience in temperate regions may be inappropriate for tropical regions. This difference is not just a consequence of differ- 

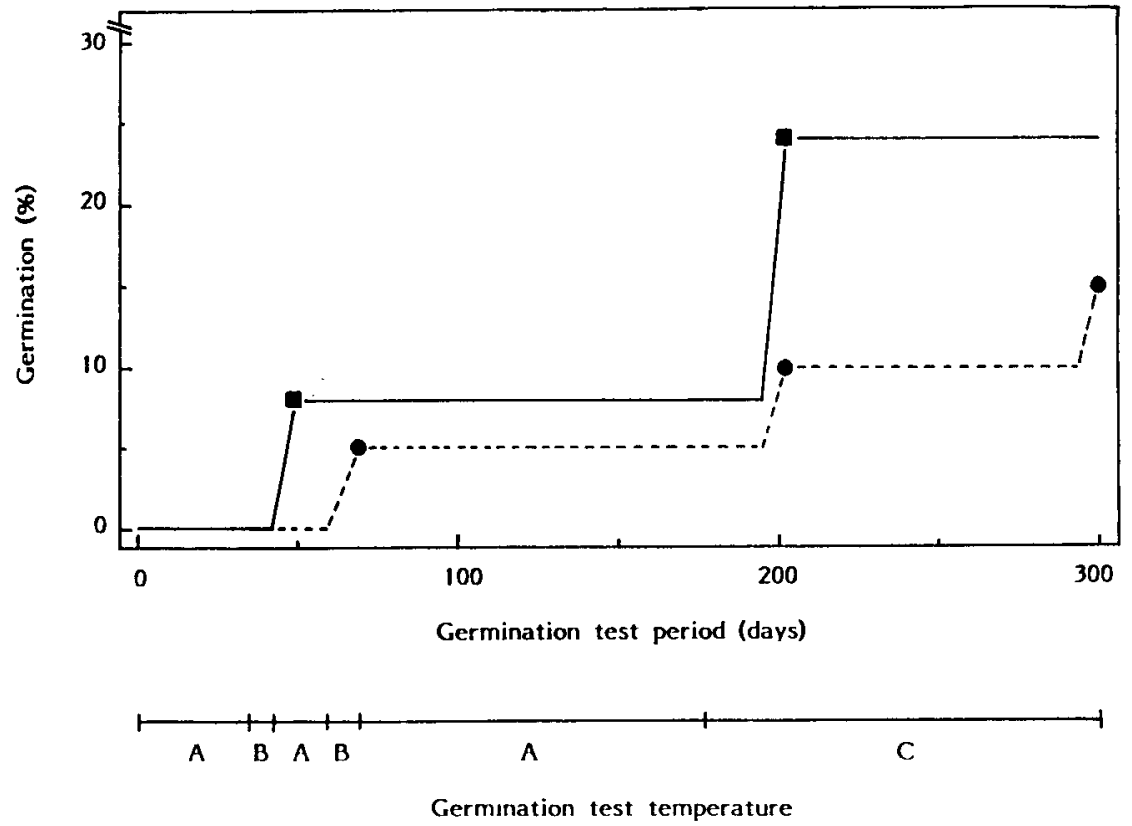

Fig. 10. The progress of germination of intact seeds of Musa acuminata ( $\mathbf{0})$ and Musa balbisiana ( ) following drying to $6 \%$ moisture content. The seeds were transferred between constant and alternating temperatures at various times: $A=25 \mathrm{C} ; \mathrm{B}=15 / 35 \mathrm{C}(16 \mathrm{~h} / 8 \mathrm{~h}) ; \mathrm{C}=20 / 35 \mathrm{C}(16 \mathrm{~h} / 8$ h). Germination tests were inspected weekly; symbols are shown only when seeds germinated (Ellis, Hong, and Roberts, unpublished).

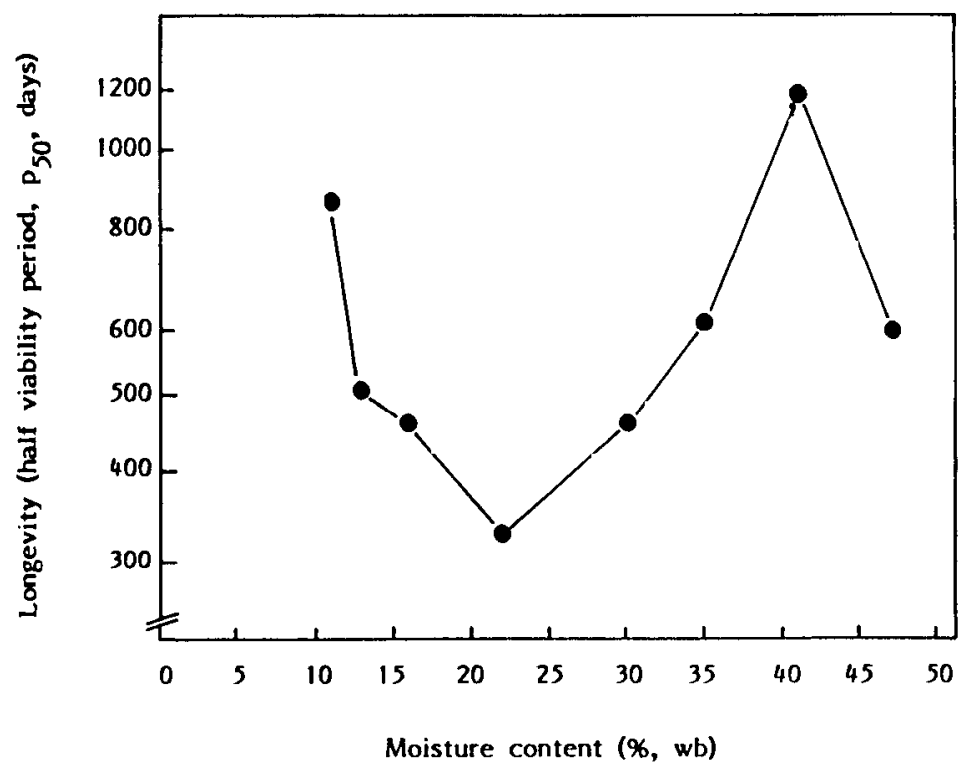

Fig. 11. Relationship between the time taken for coffee seed (Coffea arabica L.) viability to fall to $50 \% \mathrm{p}_{50}$, logarithmic scale) and seed moisture content when stored at $15 \mathrm{C}$. Data from Van der Vossen (1979).

ences in the ambient storage environments, but also because of potential differences in seed production environments that can affect potential longevity. The viability equation (Eq. [3]) and the determination of the lowmoisture-content limits to this equation provide a sound foundation for providing advice in such circumstances.

Some tropical crops possess recalcitrant seeds. In these cases, only short-term storage is possible. At least two tropical crops possess seeds that show an intermediate category of seed storage behavior. It is not yet
Berjak, P., J.M. Farrant, D.J. Mycock, and N.W. Pammenter. 1990. Recalcitrant (homoiohydrous) seeds: the enigma of their desiccationsensitivity. Seed Sci. Technol. 18:297-310.

Chin, H.F. 1988. Recalcitrant seeds - a status report. Intl. Board for Plant Genet. Resources, Rome.

Chin, H.F., M. Aziz, B.B. Ang, and S. Hamzah. 1981. The effect of moisture and temperature on the ultrastructure and viability of seeds of Hevea Brasilensis. Seed Sci. Technol. 9:411422.

CIAT. 1987. True seed for commercial cassava production. CIAT Intl. 6:10-16.

Dickie, J.B., R.H. Ellis, H.L. Kraak, K. Ryder, and P.B. Tompsett. 1990. Temperature and seed storage longevity. Ann. Bot. 65:197-204.

Ellis, R.H. 1988. The viability equation, seed viability nomographs, and practical advice on seed storage. Seed Sci. Technol. 16:29-50.

Ellis, R.H. and E.H. Roberts. 1977. A revised seed viability nomograph for onion. Seed Res. 5:93-103.

Ellis, R.H. and E.H. Roberts. 1979. Germination of stored cassava seed at constant and alternating temperatures. Ann. Bot. 44:677-684.

Ellis, R.H. and E.H. Roberts. 1980a. Improved equations for the prediction of seed longevity. Ann. Bot. 45:13-30.

Ellis, R.H. and E.H. Roberts. 1980b. The influence of temperature and moisture on seed viability period in barley (Hordeum distichum L.). Ann. Bot. 45:31-37.

Ellis, R.H. and E.H. Roberts. 1981a. The quantification of ageing and survival in orthodox seeds. Seed Sci. Technol. 9:373-409.

Ellis, R.H. and E.H. Roberts. 1981b. An investigation into the possible effects of ripeness and repeated threshing on barley seed longevity under six different storage environments. Ann. Bot. 48:93-96.

Ellis, R.H., T.D. Hong, and E.H. Roberts. 1981. The influence of desiccation on cassava seed germination and longevity. Ann. Bot. 47:173175.

Ellis, R.H., T.D. Hong, and E.H. Roberts. 1982a. An investigation of the influence of constant and alternating temperature on the germination of cassava seed using a two-dimensional temperature gradient plate. Ann. Bot. 49:241-246.

Ellis, R.H., K. Osei-Bonsu, and E.H. Roberts. 1982b. The influence of genotype, temperature and moisture on seed longevity in chickpea, cowpea and soya bean. Ann. Bot. 50:69-82.

Ellis, R.H., T.D. Hong, and E.H. Roberts. 1985. Handbook of seed technology for genebanks. Volume II. Compendium of specific germination information and test recommendations. Intl. Board for Plant Genet. Resources, Rome.

Ellis, R.H., T.D. Hong, and E.H. Roberts. 1986. Logarithmic relationship between moisture content and longevity in sesame seeds. Ann. Bot. 57:499-503.

Ellis, R.H., T.D. Hong, and E.H. Roberts. 1987. The development of desiccation-tolerance and maximum seed quality during seed maturation in six grain legumes. Ann. Bot. 59:23-29.

Ellis, R.H., T.D. Hong, and E.H. Roberts. 1988. A low-moisture-content limit to logarithmic relations between seed moisture content and longevity. Ann. Bot. 61:405-408.

Ellis, R.H., T.D. Hong, and E.H. Roberts. 1989. A comparison of the low-moisture-content limit to the logarithmic relation between seed moisture and longevity in twelve species. Ann. Bot. 63:601-611.

Ellis, R.H., T.D. Hong, and E.H. Roberts. 1990a. Moisture content and the longevity of seeds of Phaseolus vulgaris. Ann. Bot. 66:341-348.

Ellis, R.H., T.D. Hong, and E.H. Roberts. 1990b. 
An intermediate category of seed storage behaviour? I. Coffee. J. Expt. Bot. 41:1167-1174.

Ellis, R.H., T.D. Hong, E.H. Roberts, and K.L. Tao. 1990c. Low-moisture-content limits to relations between seed longevity and moisture. Ann. Bot. 65:493-504.

Ellis, R.H., T.D. Hong, and E.H. Roberts. 1991a. An intermediate category of seed storage behaviour? II. Effects of provenance, immaturity, and imbibition on desiccation-tolerance in coffee. J. Expt. Bot. 42:653-657.

Ellis, R.H., T.D. Hong, and E.H. Roberts. 1991b. Effect of storage temperature and moisture on the germination of papaya seeds. Seed Sci. Res. 1:69-72.

Ewart, A.J. 1908. On the longevity of seeds. Proc. Royal Soc. Victoria 21:1-120.

Goldbach, H. 1979. Imbibed storage of Melicoccus bijugatus and Eugenia brasiliensis (E. dombeyi) using abscisic acid as a germination inhibitor. Seed Sci. Technol. 7:403-406.

Grout, B.W.W., K. Shelton, and H. W. Pritchard. 1983. Orthodox behaviour of oil palm seed and cryopreservation of the excised embryo for genetic conservation. Ann. Bot. 52:381-384

Harrington, J.F. 1972. Seed storage and longevity, p. 145-245. In: T.T. Kozlowski (ed.). Seed biology, vol. III. Academic. New York.

Hong, T.D. and R.H. Ellis. 1990. A comparison of maturation drying, germination, and desiccation tolerance between developing seeds of Acer pseudoplatanus L. and Acer platanoides L. New Phytol. 116:589-596.

Hor, Y.L., H.F. Chin, and M.Z. Karim. 1984. The effect of seed moisture and storage temperature on the storability of cocoa (Theobrome cacao) seeds. Seed Sci. Technol. 12:415-420.

Ibrahim, A.E. and E.H. Roberts. 1983. Viability of lettuce seeds. I. Survival in hermetic storage. J. Expt. Bot. 34:620-630.

Ibrahim, A.E., E.H. Roberts, and A.J. Murdoch. 1983. Viability of lettuce seeds. II. Survival and oxygen uptake in osmotically controlled storage. J. Expt. Bot. 34:631-640.

King, M.W. and E.H. Roberts. 1979. The storage of recalcitrant seeds-achievements and possi- ble approaches. Intl. Board for Plant Genet. Resources, Rome.

King, M.W. and E.H. Roberts. 1980a. Maintenance of recalcitrant seeds in storage, p. 5389. In: H.F. Chin and E.H. Roberts (eds.). Recalcitrant crops seeds. Tropical Press, Kuala Lumpur.

King, M.W. and E.H. Roberts. 1980b. The desiccation response of seeds of Citrus limon L. Ann. Bot. 45:489-492.

King, M.W. and E.H. Roberts. 1982. The imbibed storage of cocoa (Theobroma cacao) seeds. Seed Sci. Technol. 10:535-540.

King, M.W., U. Soetisna, and E.H. Roberts. 1981. The dry storage of Citrus seeds. Ann. Bot. 48:865-872.

Kraak, H.L. and J. Vos. 1987. Seed viability constants for lettuce. Ann. Bot. 59:343-349.

Mumford, P.M. and B.W.W. Grout. 1978. Germination and liquid nitrogen storage of cassava seed. Ann. Bot. 42:255-257.

Mumford, P.M. and B.W.W. Grout. 1979. Desiccation and low temperature $\left(-196^{\circ} \mathrm{C}\right)$ tolerance of Citrus limon seed. Seed Sci. Technol. 7:407-410.

O'Dowd, E.T. and P. Dobie. 1983. Reducing viability losses in open seed stores in tropical climates. Seed Sci. Technol. 11:57-75.

O'Dowd, E.T., S.M. Kenneford, A.J.K. Bisbrown, and J. Farrington. 1988. A mathematical model, with cost implications, for predicting temperatures in seed stores. Overseas Dev. Natural Resources Inst. Bul. 16.

Pammenter, N.W., J.M. Farrant, and P. Berjak. 1984. Recalcitrant seeds: Short-term storage effects in Avicennia marina (Forsk.) Vierh. may be germination-associated. Ann. Bot. 54:843846.

Petruzzelli, L. 1986. Wheat viability at high moisture content under hermetic and aerobic conditions. Ann. Bot. 58:259-265.

Roberts, E.H. 1961. Viability of cereal seed for brief and extended periods. Ann. Bot. 25:373380.

Roberts, E.H. 1972. Storage environment and the control of viability, p. 14-58. In: E.H. Roberts (ed.). Viability of seeds. Chapman and Hall. $\mathrm{L}$ o $\mathrm{n} \mathrm{d}$ o $\mathrm{n}$.

Roberts, E.H. 1973. Predicting the storage life of seeds. Seed Sci. Technol. 1:499-514.

Roberts, E.H. and F.H. Abdalla. 1968. The influence of temperature, moisture, and oxygen on period of seed viability in barley, broad beans. and peas. Ann. Bot. 32:97-117.

Roberts, E.H., M. W. King, and R.H. Ellis. 1984. Recalcitrant seeds: their recognition and storage, p. 38-52. In: J.H.W. Holden and J.T. Williams (eds.). Crop genetic resources: Conservation and evaluation. George Allen and Unwin, London.

Soetisna, U., M.W. King, and E.H. Roberts. 1985. Germination test recommendations for estimating the viability of moist or dry seeds of lemon (Citrus limon L. Burm.) and lime (C. aurantifolia (Christm.) Swing.). Seed Sci. Technol. 13:87-110.

Tompsett, P.B. 1986. The effect of temperature and moisture content on the longevity of seed of Ulmus carpinifolia and Terminalia brassii. Ann. Bot. 57:875-883.

Van der Vossen, H.A.M. 1979. Methods of preserving the viability of coffee seed in storage. Seed Sci. Technol. 7:65-74.

Villiers, T.A. 1973. Ageing and the longevity of seeds in field conditions, p. 265-288. In: W. Heydecker (ed.). Seed ecology. Butterworths, London.

Villiers, T.A. 1975. Genetic maintenance of seeds in imbibed storage, p. 297-315. In: O.H. Frankel and J.G. Hawkes (eds.). Crop genetic resources for today and tomorrow. Cambridge University Press. Cambridge. U.K.

Villiers, T.A. and D.J. Edgcumbe. 1975. On the causes of seed deterioration in dry storage. Seed Sci. Technol. 3:761-774.

Ward, F.H. and A.A. Powell. 1983. Evidence for repair processes in onion seeds during storage at high seed moisture contents. J. Expt. Bot. $34: 277-282$.

Zewdie, M. and R.H. Ellis. 1991. The uppermoisture-content limit to negative relations between seed longevity and moisture in niger and tef. Seed Sci. Technol. (In press.) 